\title{
Connecting Environmental Action to E-participa- tion Design for Young People
}

\section{Stefano De Paoli and Paula Forbes}

Sociology Division, Abertay University, Dundee (UK), s.depaoli@abertay.ac.uk p.forbes@abertay.ac.uk

The paper offers a conceptual analysis and a case study research on the design of e-participation in environmental policy-making for young people. This is achieved by connecting the concept of environmental action with e-participation design. Through a literature review, four core dimensions of environmental action for young people are identified: ownership, participation, stakes in the future and experience. Through a case study of research conducted for an applied project aimed at designing and piloting a novel e-participation solution, the paper shows how young people, implicitly see the connections between these four dimensions of environmental action and the e-participation process. The dimensions of environmental action have then been used as the basis for co-creation activities and for a subsequent evaluation of e-participation. The results support the position that environmental action can underpin the design and can increase e-participation capacity in environmental policy-making for young people.

Keywords: e-participation, environmental action, trust, experience, young people, future

\section{Introduction}

This paper's main contribution to research and practice ${ }^{1}$ will be to show how the concept of environmental action can underpin the design of an e-participation platform prototype supporting young people's involvement in environmental policy-making. The concept of environmental action points to the capacity of individuals and groups to take deliberate and proactive decisions in order

\footnotetext{
${ }^{1}$ This paper has received support from the European Union's Horizon 2020 research and innovation programme under grant agreement No 649493." The paper reflects only the author's view and the Research Executive Agency or European Commission is not responsible for any use that may be made of the information it contains. The authors would like to thank the project partners, all the project participants and the two anonymous reviewers of the journal. Authorship of the manuscript is shared equally between the authors. Paula Forbes has conducted all the data collection and analysed early interviews and co-creation material. Stefano De Paoli has designed the research, analysed the questionnaire and evaluation material and led the writing of the manuscript.
} 
to achieve a desired environmental outcome (Emmons, 1997, Schusler et al., 2009). e-participation has been defined by Sæbø et al., 2008 (p. 400) as "the extension and transformation of participation in societal democratic and consultative processes mediated by information and communication technologies (ICT), primarily the Internet".

This work is the outcome of a European research project, aimed at designing and piloting a novel web and mobile e-participation prototype platform for Young European Adults (YEAs) aged between 16 and 29. The project was funded by the European Commission under the auspices of the EU Youth Strategy (2010-2018) (European Commission, 2018) aiming at encouraging young people to be active citizens and participate in society. As such this e-participation project was not concerned with the general public or stakeholder engagement practices and focused specifically on Young European Adults. The goal of the project was to create a platform allowing YEAs to collaborate with Policy-Makers (PMs) in the area of environmental policy-making. More details about how the project tried to tackle issues around the societal and political engagement of young people toward environmental issues can be read in the work by Vogiatzi et al. (2017). This paper instead will show specifically, using the project as a case study, how the concept of environmental action can be used as the basis for e-participation design and how this can lead to good engagement of young people in environmental policy-making.

Citizen engagement with public policy is an established concept in research and practice. However very often the traditional means of participation, for example public hearings and citizen panels, have been criticized as time- and money-consuming and low in efficiency (Zheng, 2017). The location and timing of these types of events is usually fixed and often inconvenient, for example when people are at work and the location may be hard to travel to for some and would incur a cost. There is agreement that we face a context of decline in public participation (Putnam, 2001) and often the use of Information and Communication Technologies (ICTs) is a means to increase public engagement by opening up direct channels of communication between policy-makers and the wider public. e-participation could help overcome the shortcomings of more traditional approaches and also offer citizens much more choice for action and decision making (Phang \& Kankanhalli, 2008). However, our current understanding of successful e-participation strategies and implementation is still very limited (Wirtz, Daiser, \& Binkowska, 2018). It is now accepted that just building platforms for e-participation is not enough and research has argued that the "build it and they will come approach" often does not suffice to counteract the public participation decline (Tonn, 2004). For example, some of the biggest challenges for e-participation processes (especially in the European context) are the citizens' lack of trust toward political institutions (Lironi, 2016) and the difficulties in articulating clear connections between participation and institutional legitimacy (Dalakiouridou et al., 2012). The lack of trust especially affects young people, where research has shown that the more traditional channels of representative democracy (like voting) only partially stimulate their active participation to political life (European Commission, 2013). Consequently, strategies have been developed in order to increase young people's interest toward political participation (European Commission, 2018) including the use of ICTs. Indeed, in e-participation research literature, there is substantial agreement that citizen engagement and participation can have a positive effect on citizen's trust in government (Cooper et al. 2006), which can also substantially improve governmental responsiveness toward public concerns (Buček, 2000), increase governmental legitimacy (Fung, 2006) 
and augment policy-making capacities (Percy-Smith and Burns, 2013). Research has also shown that public authorities venturing into e-participation may also gain from being seen as innovators by citizens (Mergel, 2015). Moreover, research showed that e-participation solutions have the capacity to enhance young people's education toward the democratic decision-making process (Macintosh et al. 2004) and online activities do have an influence on young people's offline political participation (Quintelier and Vissers, 2008).

Extensive research has also investigated the impact of social media and social networking sites such as Facebook on young people's social capital and civic engagement (Brandtzæg, Følstad, \& Mainsah, 2012; Xenos, Vromen, \& Loader, 2014; Mavrodieva, et al., 2019; Omotayo \& Folorunso, 2020). For example, Boulianne et al.(2020, p. 209) state that "social media can be used to question, contest, and/or support decisions or actions of media, political, private or governmental organizations". Their research relates to the recent strikes for the climate crisis and reflects a trend in international protest events, which are connected through social media and other digital media tools. Omotayo and Folorunso (2020, p. 148) in a case study in Nigeria showed that youth can use social media for a large variety of activities in the area of political participation involving among others "political advocacy, political campaign, communicating with politicians, political discussions, monitoring and reporting electoral malpractices, public consultations, joining interest groups that engage in lobbying, blogging about political issues and writing letters to public officials.". It is also notable that our research took place prior to the massive environmental awareness campaign begun by Swedish teenager Greta Thunberg. In the past 2 years there has been a huge increase in youth activism relating to the environment and this clearly also took place on social media where research has detected a change in sentiment toward the importance of the environment and has shown that social media played a role in amplifying this message (Jung et al., 2020)

Promoting public participation is a fundamental principle in European environmental law, whereby the Aarhus Convention gives the public the right to obtain information on environmental issues and participate in the related decision-making. Responding to this fundamental principle the STEP project conducted research, in order to design, develop and pilot a novel e-participation platform for YEAs engagement in environmental decision/ policy-making. It is important then to remark that the projects main goal was thus not conducting e-participation per se, but designing and testing a novel platform prototype in five municipalities and regions in four countries (Italy, Turkey, Greece and Spain). In addition to these public authorities, the project team was composed of several other organistions including a university, a research centre, a youth environmental NGO and a number of SMEs. It is important to note that one of the overall goals of the project was to create a platform that the SMEs involved in the project could then later on use for their own businesses activities, especially in the areas of promotion of environmental activities and public participation. Within the project, our group was specifically tasked with conducting social research supporting the technical partners, focusing on: (1) understanding the needs and obstacles for designing an e-participation platform for environmental policy-making, supporting YEAs and PMs; (2) conducting research to convey these needs and obstacles to the design and development teams; (3) evaluating the platform's capacity of supporting the involvement of YEAs during the piloting. 
In conducting this research, we took environmental action as the guiding concept. Consequently, the main question that this paper will seek to answer is: how can we practically connect environmental action to the design of an e-participation platform prototype for supporting young people's engagement with environmental policy-making?

\section{Environmental Attitude, Behaviour and Action}

In this section, we will discuss different concepts from the literature that can help understand the relationship of young people and young adults with the environment. As an outcome of this literature review, we will propose that the concept of environmental action can support the design of e-participation solutions for young people for environmental decision-making.

A first key conceptual distinction we need to focus on is that between environmental attitude and action. An attitude is a predisposition - positive or negative - toward specific values, people or ideas (Eagly and Chaiken, 1993). Environmental attitudes develop over time and are dependent upon demographics and social factors (Dietz et al., 1998). Social factors include aspects such as socialisation, social norms or communication processes. Research has shown that in particular socialisation may drive positive environmental attitudes especially influenced by the family, formal education and peers (de Vreede et al. 2014; Grønhøj and Thøgersen, 2009). The media (including online) can also offer a basis for pro-environmental socialization (Östman, 2014; European Commission, 16). Demographic factors are instead structural elements of society and include aspects such as age, social class, residence (urban/rural), political orientation and sex/gender (Van Liere and Dunlap, 1980). The assumption made by proponents of the concept is that variations in demographic factors have a causal influence toward positive or negative environmental attitudes. However, research has produced contrasting results. For example, one research paper has shown that females seem more concerned than males about the environment e.g. (Zelezny, 2000). Another contribution however, has shown little difference between the environmental attitudes of males and females (Tindall et al. 2003). Environmental concern has also been positively associated with income or occupational prestige (Van Liere and Dunlap, 1980). However, other research (Wilson and Snell, 2010) has shown that people with limited material resources are particularly affected by environmental problems and may consequently have a significant level of engagement.

In designing environmental e-participation for YEAs, we suggest that leveraging on the notion of attitude will have limits. An e-participation design is unlikely, in the short term (such as the timeframe of a single research project), to have the ability to influence social factors (e.g. increase participants' education levels), although this may be possible over a longer period of time, and has no capacity to influence demographic factors. Moreover, discriminating among participants on the basis of, for example, their education or income is not commendable. Rather than focusing on attitudes, we suggest that a better approach for the design of environmental e-participation for YEAs is to focus on supporting environmental action. That of social action is a fundamental concept in social sciences and captures the idea that an agent intentionally orients his/her doing toward specific ends or values, while taking in account other actors (Weber, 1922). In line with this, environmental action 
was defined by Emmons (1997, p.35) as "a deliberate strategy that involves decisions, planning, implementation, and reflection by an individual or a group. The action is also intended to achieve a specific positive environmental outcome, either small or large".

An additional important distinction we need to focus on is that between environmental behaviour and action. In both cases, the actors may be doing something leading to a positive environmental outcome, which would suit active e-participation, but there is a fundamental difference. While pro-environmental behaviour is likely habitual, actions require intention (de Vreede et al., 2014) and are oriented toward tackling the causes of environmental issues. Changes in behaviour (e.g. ensuring people use public transport rather than the car) can be triggered by positive or negative reinforcements (e.g. increasing costs for parking or reducing public transport fares), but this does not mean that the actor is aware of the root-causes of environmental issues or that she is intentionally intervening on these causes. We suggest further that the notion of environmental behaviour also cannot support the design of e-participation, since actively participating in policy-making requires intentionality and pro-activity from participants. We can understand this more clearly by considering the concept of action competence (Jensen and Schnack, 1997; Breiting and Morgensen, 1999). This concept is a critique to environmental educational approaches that focus on triggering changes of behaviour rather than on stimulating intentions to tackle causes of environmental issues. Action competence also criticizes individualistic approaches and emphasizes participatory processes. According to Jensen and Schnack (1997, p. 165) "'Competence' is associated with being able, and willing, to be a qualified participant". This is in line with a definition of environmental action by Schusler et al. (2009, p. 122) as "a process of co-creating environmental and social change that builds individuals' capabilities for further participation contributing to personal and community transformation". These definitions contain strategic aspects and we have identified four relevant dimensions of environmental action and action competence in literature (also summarized in Table 1), that can constitute the basis for environmental e-participation design:

1) Youth ownership and empowerment: this includes aspects such as the young people seen as agents of change (de Vreede et al., 2014) and the availability of spaces where young people can take ownership of their actions. Indeed, as Percy-Smith and Burns (2013, p. 336) articulated: "Central to promoting the increasing role of young people as agents of change in communities is the provision of spaces which are not always controlled by adults or defined by the adult agenda but which also provide opportunities for young people to take action in response to issues they feel passionate about".

2) Participation: research on environmental action (e.g. see definition above by (Schusler et al. 2009) has emphasised the importance of peer participation and co-creation with actions conducted via participatory and democratic mechanisms, where individuals join forces and bring their capacity to contribute to socio-environmental transformations.

3) Stakes in the future: a key motivation for environmental action is the need to protect the environment for future generations (Ballantyne, 1995). According to de Vreede et al. (2014, p. 37) "Committed and action-competent young people provide a valuable force, which can influence change as they have a great investment in future quality of life and can approach problems with a fresh, optimistic view".

4) The experiential component: environmental action is not related to abstract environmental principles but rather with young people's direct and own experience de Vreede et al. (2014, p. 37; 
Bögeholz, 2006). This means that the issues that mean most to them are the ones that have a direct impact on their lives.

Table 1: Concepts and their potential connection with environmental e-participation design

\begin{tabular}{|c|c|}
\hline Concept & $\begin{array}{l}\text { Usable in the design of e-participation on environmental } \\
\text { issues? }\end{array}$ \\
\hline Environmental Attitude & $\begin{array}{l}\text { Does not involve taking a proactive stance. Attitudes develop } \\
\text { over time and are unlikely to be influenced by an e-participa- } \\
\text { tion design process alone. }\end{array}$ \\
\hline Environmental Behaviour & $\begin{array}{l}\text { Does involve "doing something" habitually, but does not re- } \\
\text { quire intention. Does not help in e-participation where young } \\
\text { people should engage to tackle causes and concerns of envi- } \\
\text { ronmental problems. }\end{array}$ \\
\hline Environmental Action & $\begin{array}{l}\text { Can support e-participation design, as the focus is on young } \\
\text { people willing to achieve pro-environmental outcomes by } \\
\text { working together on things that matter directly to them. }\end{array}$ \\
\hline
\end{tabular}

\section{The STEP Project}

In this section, we briefly introduce the STEP2 European project upon which this research paper is based and which is used as a case study to show how to connect environmental action and environmental e-participation design. During the project, five pilots were conducted in four countries for testing the prototype: Italy, Spain, Greece and Turkey, with the participation of one regional authority, three municipalities, and an association of municipalities. The piloting involved nearly seven thousand YEAs and ninety-one PMs, over two and a half years, producing eighty-eight dialogues. Our role within the project was supporting the technical team in understanding the needs of YEAs and PMs in relation to the platform design and piloting.

The project's main goal was to develop and pilot test a cloud e-participation platform supporting environmental policy-making and deliver a near to market solution. The STEP platform consists of four main cloud based components, which are: 1) the e-participation component, 2) the social media mining and visualization component, allowing the integration and use of resources for e-participation with the wider social media environment, 3) a machine translation and text to speech component supporting multilingualism and 4) the data logging components managing the platform's data. The cloud solution allows for the seamless integration of these components which were developed by different project partners using different technologies. More details about the technical aspects of the cloud based solution are available in this project deliverable by Yümlü et al. (2016). The eparticipation component is the core of the platform, supporting the interaction between YEAs and PMs in the respective local authorities and supporting the communication of/with the other components of the platform. The e-participation component includes all the end-users interfaces. This

${ }^{2}$ For further details consult the project website http://step4youth.eu/ 
component was not created from scratch but was based on a previous existing collaborative platform belonging to one of the project partners and called co:tunity (https://www.cotunity.com/).

The platform supports both top-down and bottom up approaches to e-participation (Vogiatzi et al. 2017). During the project's initial phases a set of use-cases (named "dialogues") were defined by the project team with the active collaboration of the local authorities, for piloting the platform prototype. The top-down dialogues can be initiated by PMs and include Consultation, Consultation on Environmental Impact Assessments (CEIA) or Round Table discussions. The platform also allows for bottom-up dialogues, these can be initiated by YEAs and include Call for petitions and Call for ideas. These use-cases were identified through the definition of a framework for public participation created by combining information from available best practice guidelines and toolkits and adapting it to the STEP project specificities (Vogiatzi et al., 2017). Choices around the use-cases and the piloting activities for the platforms were then taken, under the umbrella of this framework, together with the public auhtorities involved in the project and based on their knowledge of the specific issues that would matter for their youth. Moreover, the choice of the content of the initial dialogues to be conducted through the platform was informed by carrying out a 'Cultural Probe' study, lasting for four weeks. Cultural probes are studies that include open-ended and evocative activities for participants to pursue in their own time to help narrate their lives to technology designers. Using an early prototype of the platform we involved an initial small number of young people $(n=16)$ in a digital cultural probe requiring posting content responding to specific prompts coming from the researchers. Results of this probe allowed us to indentify what should be the initial focus for the STEP dialogues with the following areas emerging as relevant for YEAs: sustainable transport, food and reducing waste / recycling. Moreover the probe confirmed the importance for YEAs to receive timely feedback on their inputs, the importance of nurturing youth leadership in public participation via the platform and the importance of favouring a collective mentality based on that idea that YEAs by working together could make a difference for the environment. The results of the probe study can be consulted in the paper by Forbes and De Paoli (2016).

The regular use of the platform from the YEAs perspective is as follows. Once YEAs sign up to the platform they can view all the available dialogues for their municipality/region/local area and can participate in them. The most commonly used dialogue during the piloting activities was for local PMs to open up a consultation on a specific issue (e.g. management of environmental resources in the area) to obtain YEAs' ideas (for example, on protecting Sea Turtles in Greece or for an urban garden in Spain). In a consultation, the environmental issue is presented by PMs with supporting material (images, files, videos, etc.) and a specific question is posed to participating YEAs (e.g. what should the authority do for protecting our Sea Turtles?). YEAs are then invited to contribute via a variety of options, including multiple choices, yes-no questions, open free-texts and comments. The consultation remains open for a period of time and the inputs are visible to all participants. At the end, the results of the consultation are analysed and a report on which actions will be taken by PMs is published in the platform. The bottom up dialogue, Call for ideas, was also used during the pilots. In this case PMs ask to YEAs to propose ideas, for example, for redeveloping a chosen area in a Spanish municipality where the remit of the public authority was specified in advance, for example a budget of 100,000 Euros. YEAs can then vote for the proposed ideas and PMs make a clear commitment to consider those ideas which have received a minimum number of votes. 


\section{Methods and Materials}

It is widely accepted in design research that end-users can be a rich source of product and service innovations (Prahalad and Ramaswamy, 2000) and that their involvement in the initial phases of design can better support the uptake of new ICT solutions. Although, during the project, we also worked with PMs, in this paper we concentrate mostly on YEAs, as they were the core target users. The main rationale underpinning our research method for researching the end-user needs was that of connecting the concept of environmental action previously described with a user-centered design of the platform. We worked toward ensuring that the four core dimensions of the concept of environmental action could be translated in the prototype e-participation platform under the assumption that this would better support environmental participation from YEAs. Our empirical research, which saw a continuous and active involvement of YEAs and PMs over two years and a half, was organized in three main phases (Fig. 1): (1) early interviewing with YEAs and PMs to gather their environmental action needs and the deployment of a cultural probe with YEAs, using a prototype of the platform as described earlier (Forbes \& De Paoli, 2016); (2) building personas reflecting environmental action needs of the users and co-creation with participants, by transforming some of the personas' needs into concrete design ideas; (3) a final evaluation of whether participants environmental action needs were met by the platform during the piloting. Additionally, as the platform needed to fulfill the needs of all end-users across different pilots (and Europe more widely), we concentrated on their common needs rather than on specific national or regional differences.

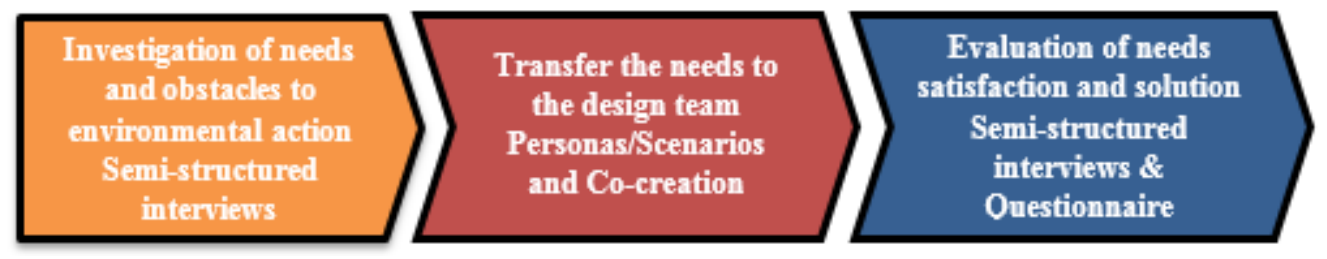

\section{Fig. 1. Social research phases of the project}

The goal of interviewing YEAs early in the project was important to understand how the platform's features could facilitate their environmental action. As part of the initial research phase, we interviewed 28 YEAs from 9 EU Countries (thus including YEAs from beyond the piloting areas in United Kingdom, Germany, France, Hungary, Romania and Latvia). We used a purposive sampling, with participants identified by the project partners.

Subsequently, findings from the interviews were used for the creation of personas and scenarios. Personas are "user archetypes" that help developers take decisions about design solutions by adopting a user-centered perspective. Personas are models of real users whose traits "are identified through the analysis of interview data" (Cooper et al. 2007, p. 82). Scenarios are narratives of the personas interacting with the future product or service. It is through personas and scenarios that our findings on the end-users' environmental action needs were passed to the technical partners of the 
project. Later in the paper, we will concentrate mainly on the personas creation and on the connection between our interviews findings on YEAs environmental action and the creation of personas for environmental e-participation.

We then conducted co-creation workshops (listed in Table 2) mostly with YEAs and also some with PMs, with one session including both groups. The purpose of the co-creation was to bring the environmental action needs of end-users, as mediated by the Personas, within the design process, so that these needs could translate into initial design ideas. We began by carrying out workshops early in the project and continuing throughout the middle stages. Results have been fed back to developers to enable the co-created solutions to be considered and when possible (thus not always, due to some limits imposed by the pre-existing technologies used by the project) incorporated into the testing platform.

Two simple exercises were used during the core set of workshops with YEAs (workshops 2 to 6), with the goal to generate a wide range of ideas for furthering the needs of personas. Later we will present results mainly from these core workshops. By working in small groups:

- YEAs were invited to co-design the platform's features for the personas. Each group's best idea was then presented by a spokesperson and discussed with all participants.

- YEAs were assigned one of the personas and asked to sketch ideas for an interface that this persona would find appealing.

In additional co-creation workshops (1, 7 and 8) specific elements of the platform and of the interaction between PMs and YEAs were explored: for example workshop 1 focused on exploring how to make the platform fun and engaging for young people; workshop 7 focused on the issue of trust (or the lack thereof) between YEAs and PMs, where we used card-sort exercises to prioritise the importance of various elements contributing to increasing trust between the two groups. In the final workshop (8) we worked with a group of young people from a disadvantaged background to ensure that the needs of this 'hard to reach' group were also considered. 
Table 2. Co-creation workshops on Users needs

\begin{tabular}{|c|c|c|c|}
\hline Workshop Nr. & Country & Participants & Focus \\
\hline 1 & UK & 33 YEAs & $\begin{array}{l}\text { Engage- } \\
\text { ment/Fun }\end{array}$ \\
\hline 2 & Spain (1) & 21 PMs & $\begin{array}{l}\text { Ensuring Ele- } \\
\text { ments for Services } \\
\text { match }\end{array}$ \\
\hline 3 & Czech Republic & 7 YEAs & $\begin{array}{l}\text { General Design } \\
\text { Elements }\end{array}$ \\
\hline 4 & Spain (2) & 12 YEAs & $\begin{array}{l}\text { Personalisation } \\
\text { Elements }\end{array}$ \\
\hline 5 & Turkey & 21 YEAs & $\begin{array}{l}\text { Personalisation } \\
\text { Elements }\end{array}$ \\
\hline 6 & Italy & 15 YEAs & Interactions \\
\hline 7 & Greece & $\begin{array}{l}20 \text { Mix YEAs } \\
\text { /PMs }\end{array}$ & Issues of Trust \\
\hline 8 & UK & $\begin{array}{l}8 \text { YEAs (from a } \\
\text { disadvantaged } \\
\text { background) }\end{array}$ & $\begin{array}{l}\text { Explore current } \\
\text { Design elements }\end{array}$ \\
\hline
\end{tabular}

In the third phase of the research, a combination of qualitative and quantitative techniques was used to evaluate whether the environmental action needs of end-users were met by the piloting eparticipation platform. We adopted a self-completion, online questionnaire ( $n=181$ YEAs). The questionnaire included mostly Likert scales (Strongly Agree, Agree, Neither, Disagree, Strongly Disagree), in order to collect evidence on the achievements of the project goals, environmental action needs satisfaction and future use of the platform. We had a balanced distribution among female $(47 \%)$ and male $\left(52.5 \%^{3}\right)$ respondents. As part of the evaluation, we also conducted qualitative interviews, (with a purposive sample of 12 YEAs and 9 PMs who participated to the piloting) in order to have more in-depth evaluation evidence. Later on, we will also present interview excerpts from PMs, as there are interesting observations to make. The interview protocols and the questionnaire can be consulted in the project reports (De Paoli \& Forbes, 2015; Forbes \& De Paoli, 2017).

For the questionnaire data, we produced descriptive statistics showing aggregate results of the evaluation. All the qualitative interviews were analysed using Thematic Analysis (Braun and Clarke, 2006). The four dimensions of environmental action were assumed initially as the core themes for the analysis. Moreover, we took a phenomenological angle in our thematic analysis seeking to describe the range in which quite different people (YEAs from different countries) can experience the

${ }^{3}$ The missing $0.5 \%$ refers to "other" genders 
same phenomenon (environmental action and e-participation) and identify the common components that are responsible for that range. We have provided an overview of this analysis method in a separate paper (Wilson et al., 2018).

\section{User Needs Research}

\subsection{Participation theme and trust}

We have seen earlier in the literature that a relevant dimension of environmental action is participation. First, we need to note that in an environmental e-participation project, the participation is not just that taking place among peers (YEAs) but it requires YEAs participating together with PMs. From the analysis of interviews, it emerged clearly that there are issues of trust between these two groups. This is in line with previous literature findings, mentioned in the introduction of the paper, about the lack of trust that the public has toward politics, but there are further observations relating specifically to e-participation. From our interviews, it emerged that YEAs felt that PMs could use the e-participation for their own political interests, rather than for seeking a genuine input to environmental policy-making:

...politicians don't give us much of their time, they are thinking of their own opportunity not about Young People. This is the first obstacle, they think first about their own situation and then the situation of the rest of the world [YEA3].

Some YEAs further argued that PMs may not take grassroots initiatives seriously:

I have seen petitions that I have been involved in then get discussed in parliament, but often there are only about 10 people in parliament, they are never discussed at peak times. It's an illusion of democracy [YEA5]

Moreover, interviewees made clear that participation also relates to the expectations that YEAs have toward an e-participation project:

Young People are motivated when they see that the things they are doing have a consequence, a result. If they see that changes happen then they will be interested and motivated. [YEA2]

These excerpts clearly show that from the YEAs perspective their sustained participation requires that their contributions are taken seriously by PMs and are transformed into concrete outcomes. This can possibly help with reducing the identified trust gap and YEAs engagement would be easier to achieve. Inaction from PMs, following e-participation, can instead only reduce the level of YEAs engagement and their trust toward politics.

\subsection{Stakes in the future theme}

A second fundamental dimension of environmental action is young people's interest toward the future. YEAs we interviewed clearly felt that they have more stakes in the future (due to them having a longer time horizon) than older generations and because of this, they saw themselves as actors that 
could take an active role in environmental e-participation. YEAs perceived significant differences between themselves and "older people" toward environmental issues:

There is a generational difference, I think my age group whole heartedly buy into environmental issues [...] whereas my dad's generation are [sic] less concerned. [YEA5]

From the interviews it also emerged that YEAs may have a direct interest in influencing environmental policy-making as this could have a long-standing impact on their lives, also in a rather idealistic sense:

We are a generation in transition, we are the ones making changes for future generations [YEA18]

Young People could create relationships with each other and share ideas on environmental issues. These are important in saving our future. [YEA3]

Some YEAs remarked that although the public should have an interest in the environmental future, there is much short-term thinking:

I don't see much of a clear conscience nowadays, people and politicians think more in the shortterm. Policies need to be for the long-term [YEA10]

I am quite pessimistic about the future of the environment. I believe people should be more concerned about it [YEA7]

It is clear from these excerpts the potential overlap between environmental action and e-participation, where YEAs have an interest in shaping policies if the goal is achieving positive long-term environmental improvements. YEAs however have a pessimistic view of the future but they acknowledge they have responsibilities toward future generations.

\subsection{Ownership theme}

What was just discussed about stakes in the future, connects directly with a further dimension of environmental action, that of young people's ownership toward environmental issues. YEAs that we interviewed felt they could be agents of change, influence others and work together:

I think it is important for young people to be engaged, we have a voice and we should describe what we are thinking about issues. [YEA9]

It's hard to influence with a single vote but with young people if you can get a lot of young people on your side. It is a large number of the population. It can influence sort of further issues. [YEA12]

YEAs also signaled some obstacles to their ownership toward environmental policy-making. Some argued that, , purposeful ideas promoted by YEAs are often not taken seriously by PMs:

Sometimes I think policy makers should help more. Sometimes the good ideas from young people they are cut off [YEA6] 
Thus, while YEAs ownership would be an important component of a potential e-participation, there also are obstacles, associated with participating together with PMs. Clearly, a novel e-participation design would need to take in account this problem.

Finally, ownership of environmental action also relates to dedicated spaces in which YEAs can do things together, using their competencies. YEAs we interviewed saw this potential in an e-participation platform:

The platform should educate and inform as well as providing an opportunity for discussion and campaigning [YEA21]

At least the people sharing their opinion on the platform will feel that they are able to make their voice heard [YEA9]

Thus from the interviews, it was clear that for YEAs, an e-participation platform may offer a space where YEAs can be agents of change influencing environmental decision-making.

\subsection{Experience theme}

A final dimension of environmental action we considered relates to things upon which young people feel they have an interest in and can have an impact on, in other words with their direct experience. In the words of one of the interviewees:

To facilitate discussion of Young People it's important to create a young discussion [....] something that is of interest to them [YEA3]

A number of interviewees stated they would be mainly interested in e-participation related to the local environment and to small manageable environmental things:

To get people interested you have to make things relative to their lives, for example if you don't do something about an environmental issue then it will have an impact on your life [YEA5]

'low-level' projects would be good to start with, start small and simple. With bigger things many people feel that they do not have enough knowledge to contribute [YEA21]

Some interviewees recognised also that global change could only take place via local change:

Global is more important, but the way to achieve this is through local action and local groups. If everyone works together and takes it bit by bit, rather than starting for a massive global scale then we might be able to do it [YEA12]

YEAs declared clearly that they were willing to engage and act on small things of their direct interest, which are close to their daily experience: focusing e-participation on local environmental issues rather than on global problems was seen as the right approach to support their participation. 


\subsection{First summary and personas}

Table 3 summarises the dimensions of environmental action and their connections to e-participation needs that emerged from our early interviews with YEAs.

Table 3: Environmental action and e-participation needs

\begin{tabular}{|l|l|}
\hline $\begin{array}{l}\text { Dimensions of } \\
\text { Environmental }\end{array}$ & $\begin{array}{l}\text { Environmental Action and e-participation: } \\
\text { expectations and needs from YEAs }\end{array}$ \\
\hline Experience & $\begin{array}{l}\text { YEAs are interested in doing e-participation } \\
\text { on local environmental matters, of direct in- } \\
\text { terest to them, where they can see concrete } \\
\text { results. YEAs have less interest to do e-par- } \\
\text { ticipation on global environmental issues. }\end{array}$ \\
\hline Stakes in the Future & $\begin{array}{l}\text { YEAs recognise they have more at stake, } \\
\text { and are keen to do e-participation to change } \\
\text { things for the future. YEAs perceive their in- } \\
\text { volvement as important to achieve change. }\end{array}$ \\
\hline Participation & $\begin{array}{l}\text { While seen as important, YEAs participa- } \\
\text { tion is highly conditioned by trust toward } \\
\text { Policy Makers and by clear expectations of } \\
\text { seeing results/changes happening. There is } \\
\text { a clear will to engage with peers for influ- } \\
\text { encing environmental policy-making. }\end{array}$ \\
\hline Ownership & $\begin{array}{l}\text { YEAs recognise that it is important to be en- } \\
\text { gaged in the process in order to make a } \\
\text { change. Ownership also exists in participat- } \\
\text { ing with others and in having dedicated } \\
\text { online e-participation platforms. }\end{array}$ \\
\hline
\end{tabular}

After the interviews, we worked on creating personas (6 representing YEAs and 2 representing PMs) and scenarios for the platforms. The conceptual kernel of our personas was built around the environmental action needs that emerged from the interviews. Our personas also included information beyond these needs (i.e. demographics, ICT skills, life details reflecting our interviewees), for making them believable archetypes of users. As an illustration, we present three YEAs personas (see also Fig. 2), also pointing to the specific environmental action needs of each of them.

In the first example, Sofia (our persona) shows interest for local action and local environmental initiatives (experience need) and is keen on doing collective action with her peers (participation need). Sofia challenges designers to consider how the e-participation platform should support the promotion of things that are of direct interest to her, while leveraging the competencies she has to collaborate with others. In a second example, Jan is keen on participation using online spaces (ownership need). Jan has an interest in completing actions for changing small things (experience/participation needs), in a context in which making small changes can improve the life for many (future 
need). Jan challenges designers to consider supporting the competencies of YEAs to take ownership on environmental action and to offer a digital space for their ownership. In a third example, Sara while showing mild interest for local initiatives (experience need) and for local change (future need) also shows mistrust toward politics and frustration about how decisions are taken by politicians (participation obstacle). Sara challenges designers to consider YEAs, which have a skeptical view toward PMs and where e-participation needs to bridge a trust gap.
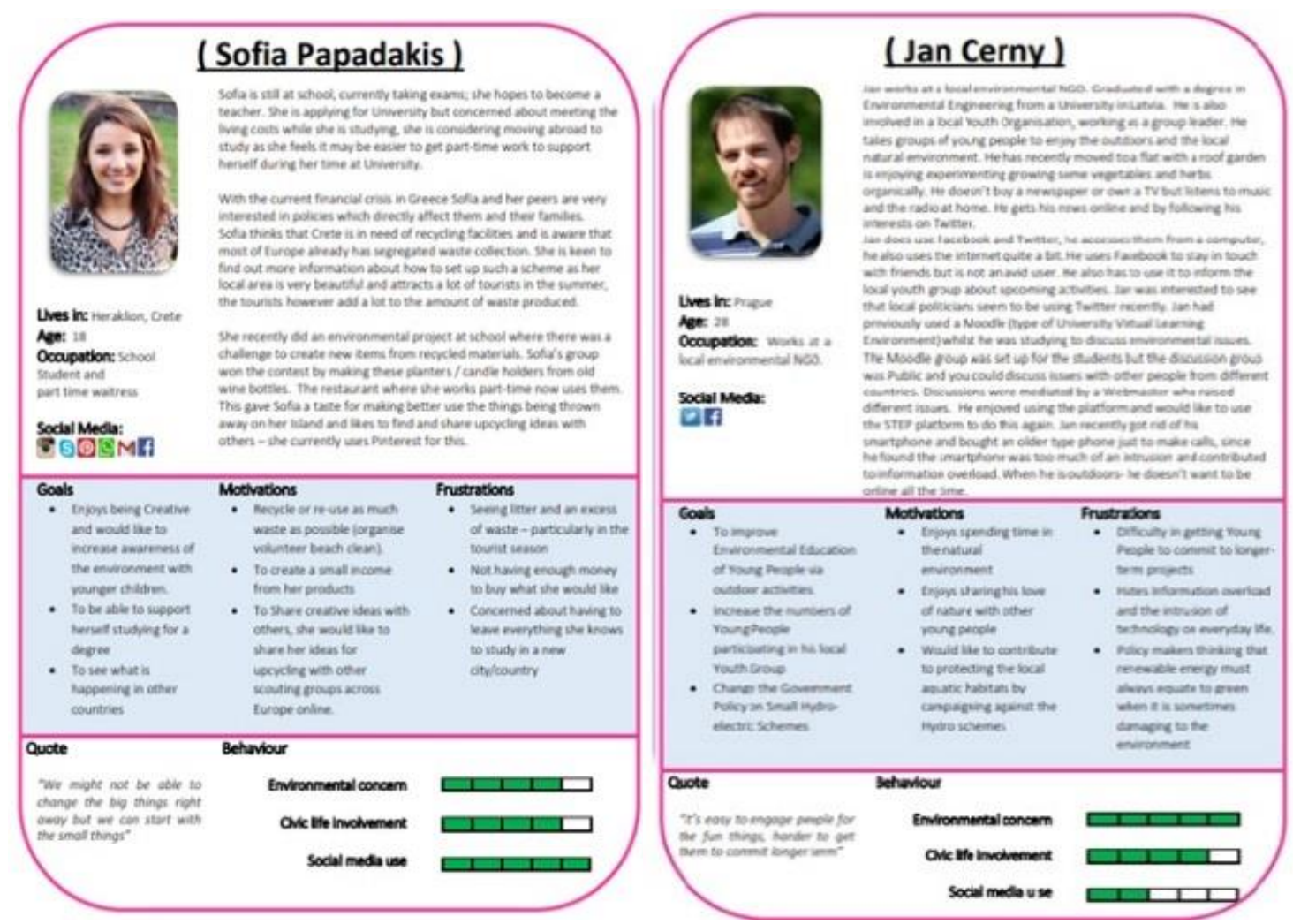


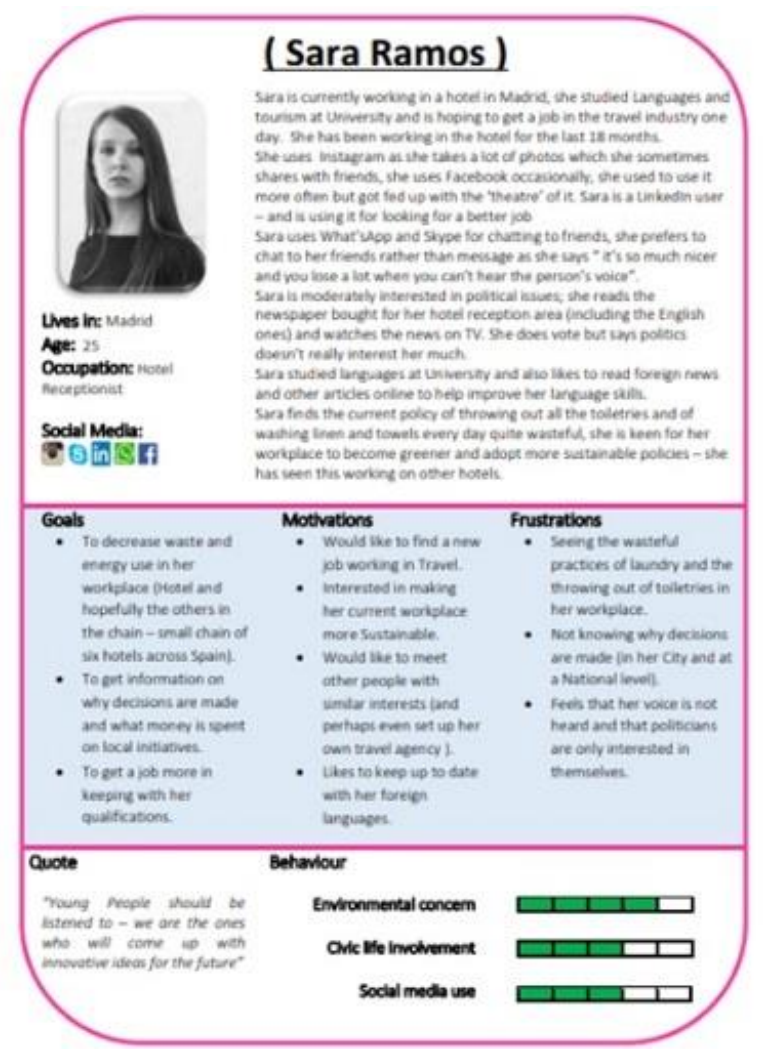

Fig. 2. Three personas from the STEP project

\section{Co-creation and Environmental Action}

We will discuss now some of the results of the co-creation research conducted for the project. The main assumption underpinning our co-creation was that YEAs were more likely to feel ownership toward the final e-participation platform by incorporating in it some of their ideas directly related to environmental action. We present results related to two of the personas seen earlier (Sofia and Jan). During a workshop in Spain (workshop 2) with YEAs, participants discussed a number of ideas for Sofia. YEAs proposed that the platform could present Sofia with a calendar highlighting relevant local and global environmental events and volunteering activities. This idea connects with the direct experience dimension of environmental action. Participants also suggested that Sofia could have the ability to start petitions (a solution for environmental action ownership) and to send these to relevant PMs, once enough signatures are reached. Workshop participants also suggested that the platform should include reports on what has been done by PMs with the e-participation inputs that Sofia could consult. This was seen as a solution to reduce the trust gap between Sofia and PMs. Participants of the workshop proposed that for Jan there could be the ability to create groups within the platform to allow him to reach out to others for arranging activities etc. This feature can be associated with the need of ownership and spaces dedicated to YEAs. A further proposition was a forum/chat that Jan could use to start dialogues with new and different people, including PMs. The option of small subscriptions with the money going to environmental causes was another feature suggested during the co-creation. Some participants said that this could get participants to think more in the 
long-term about the environment. Fig. 3 illustrates the use of the personas during the workshop and how these user archetypes were paramount for supporting the co-creation work with young people.
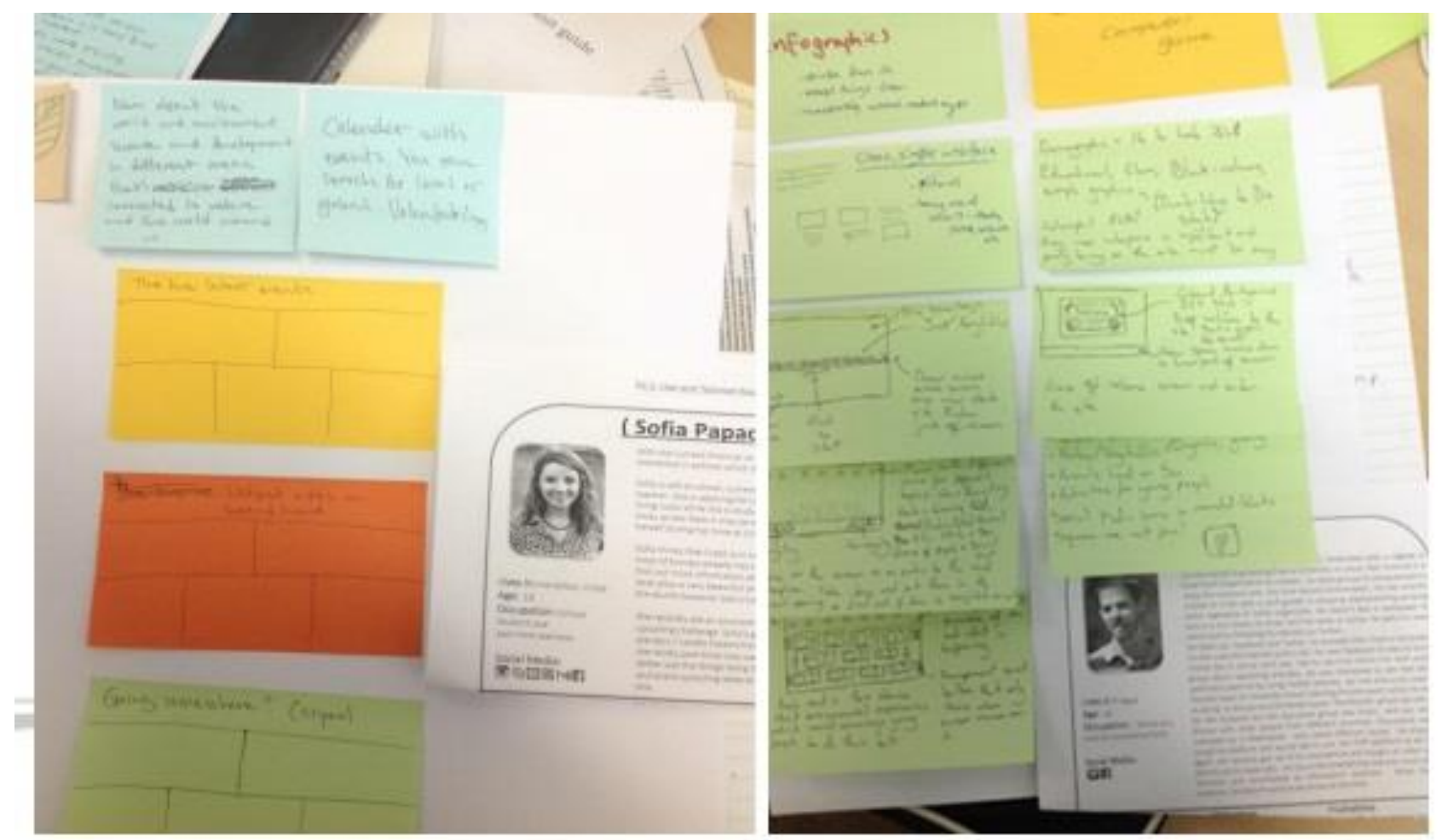

Fig. 3. Use of the personas in supporting the work with YEAs

YEAs also produced interesting ideas for the landing page of the platform. We will concentrate on three examples. In a workshop conducted in Czech Republic (workshop 3), participants placed emphasis on having the home-landing page of the platform showing what happens at a local level, where local was intended from the city/village up to a country level. This can be seen in the two sketches in Fig. 4 where both "news from the locality" and a tabs organisation of the homepage could facilitate this. However, participants also emphasized the importance of having features supporting Europe wide e-participation. For the landing page, participants also proposed a welcoming message about a "new generation" taking ownership and leading to deliver a better environmental Europe. 

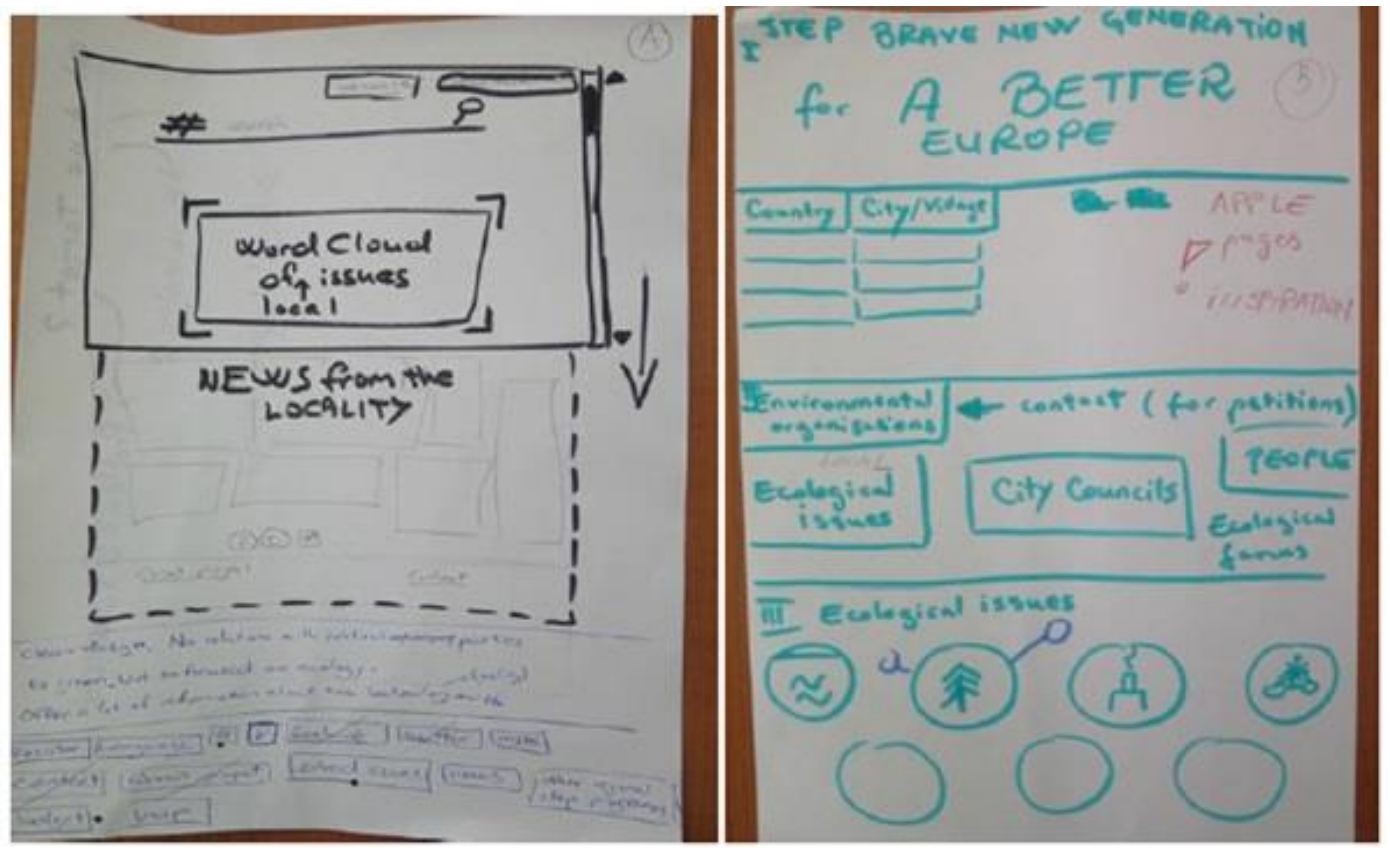

Fig. 4. Co-created landing pages ideas (Czech Republic)

In another workshop conducted in Turkey (workshop 5), participants wanted an inspiring social message on the homepage, remarking the importance of environmental values for young generations and their future. Participants also proposed a tree logo, stating that one side of the tree represented the old part of the city and the other is the new and developing part of the city, highlighting environmental issues on both sides. This group wanted to convey the message that their city is multicultural and that young people are ready to support a better environment to live in.
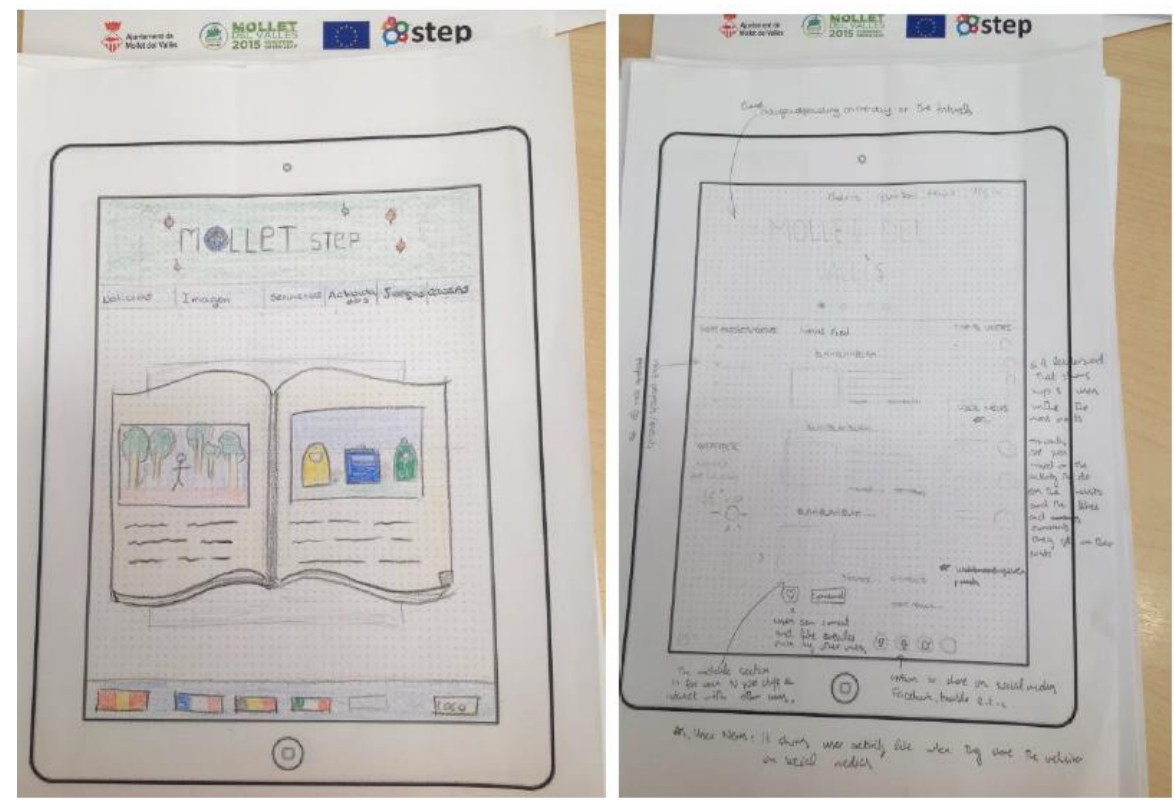

Fig. 5. Detailed sketches for a landing page proposed by YEAs (Spain) 
In a further workshop in Spain (workshop 4), participants generated very colourful and imaginative landing pages demonstrating the features that they would like to see on the platform. Some very detailed sketches were drawn as shown in Fig. 5. The features for the platform proposed by YEAs in this workshop included among others: leaderboard, projects/ events area, news feed, links for sharing via Social Media, tabs, notices/images/services, activities/games and the inclusion of local landmark symbols.

In general, the workshops also produced further confirmation that there is a lack of confidence in politicians and the belief that things will be resolved. YEAs remarked that politicians are not interested in the environmental issues and they do not seem to care what young people think. Interestingly, when young people role-played a political role during workshops, they reacted with a very strong personality and gave sanctions instead of options.

In conclusion, not all the ideas proposed by participants during the co-creation found their way into the final design of the platform (e.g. the crowdfunding) and some were already planned and designers thus received confirmation of their plans (e.g. creating petitions). However, new functionalities have arisen from the process, for example, the chat allowing participants to talk directly with other participants, the option to create small groups and the requirement to have PMs publish a report about the actions undertaken as outcome of the environmental e-participation process.

\section{Evaluation Results}

In January 2017, an advanced prototype of the e-participation platform was released for the piloting activities. Alongside the piloting, we conducted an evaluation to understand how the platform was meeting the project objectives and to understand whether the platform was ultimately capable of supporting YEAs environmental action.

\subsection{Participation theme}

From our analysis of the evaluation data, it is possible to see how the design of the platform supports YEAs' participation needs of environmental action. In the questionnaire, we asked YEAs whether the platform could increase general youth participation in environmental policy-making. An analysis of the answers show a relatively positive response at 66\% ( $n=119$, sum of Strongly Agree and Agree) and negative (excluding Neutral) at 11\% ( $n=20$, sum of Strongly Disagree and Disagree), which suggests that respondents did find good opportunities in the platform for collective participation supporting youth environmental action toward policy-making.

One core aspect of participation identified during early interviewing relates to the trust (or lack there of) between YEAs and PMs. In the questionnaire we asked YEAs whether, after they used the platform, they were more able to trust local PMs. As we can see in Fig. 6, half of the respondents $(49 \%, n=89)$ saw their capacity to trust local PMs increased, however the trust gap identified in earlier qualitative interviews still remains an aspect which the platform in itself cannot fully address (with negative responses amounting to $16 \%, n=29$, while the Neutral are at $35 \%$ ). 


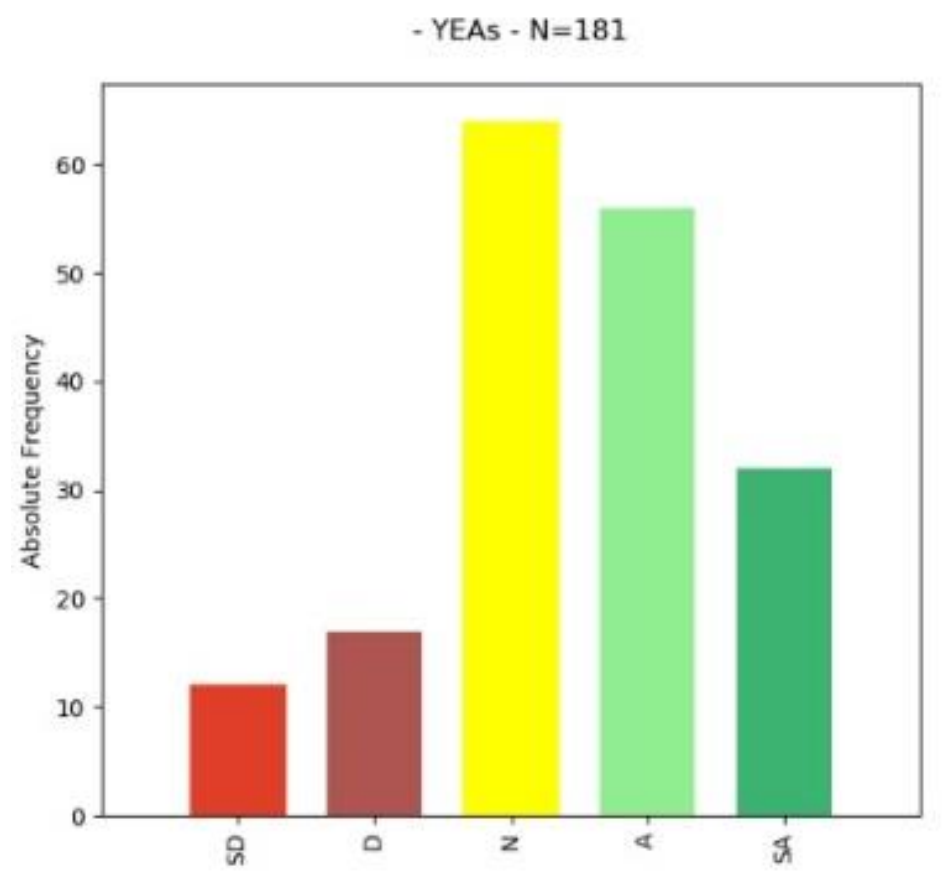

12. After using STEP I feel more able to trust local policy makers

Fig. 6. STEP and YAEs trust in local PMs

Below we present some excerpts from interviews with PMs, which illustrate why, from their perspective, the trust gap between them and YEAs still remains an issue. Respondents remarked that the challenge of building trust through e-participation will inevitably take more time:

To speak about increasing trust it's really too early. The platform can help us ease communication between the administration and the Young People, it will probably take a lot of time to build trust though. [PM_EVAL3]

The opinions that the guys bring they should actually happen to make them gain more trust. It can [take] years maybe to do something like that. [PM_EVAL1]

Indeed, while the ambition to bridge the trust gap should be part of any e-participation platform design, this also seems beyond the capacity and time-frame of a single project. Policy creation and implementation do have a different timing compared to the e-participation in itself and it will take time to see practical effects from what was piloted during the project. Nonetheless, PMs did see advantages in the transparency of the environmental policy-making process that the platform could offer, as the following excerpt well illustrates:

It's good to be direct with young people even though not all of them share the same idea but I think it helped to gain trust. It made us more familiar, more accessible. [PM_EVAL5]

The evaluation then showed that the e-participation platform did play a role in bridging the trust gap, despite PMs recognising that this will require more time. 


\subsection{Participation and expectations theme}

We have seen in earlier qualitative interviews that an important need for YEAs was that their participation in environmental decision-making is conditioned by seeing their inputs taken forward by PMs into concrete actions. In the questionnaire, we asked YEAs about the level of feedback they have received on their contributions, during the piloting activities. This question provided a positive response from $50 \%$ of participants $(n=90)$ however we also had a large component of neutral responses $(37 \%, \mathrm{n}=68)$.

Some YEAs interviewed for the evaluation saw some limits in the responses received from PMs, pointing out that the discussions in the platform did not always seem to have a clear goal:

The platform works as a first step, informing people of the issue and then getting them to express an opinion, but to really hook people you must also give them something - give them a sense of purpose [YEA_EVAL6]

The problem is not what happens with the dialogues - but what happens now. I have contributed my idea - but now what? What happens next? If I see something happen I will continue to use it - if not then I won't. I'd be happy to continue - it's fun, but I want to see results. [YEA_EVAL1]

Some excerpts from the interviews with PMs can help to better contextualise the issues and show why the platform may not have immediately produced what YEAs were expecting. Firstly, PMs were genuinely active in giving feedback and were motivated in implementing concrete actions responding to the YEAs contributions, first of all via the reports on dialogues (one of the features identified with co-creation):

Young people have been participating a lot, we have been aiming for the target numbers. Our next challenge however is to make a report on every single dialogue, then to email this report back to the users who were involved and then tell them what's going to happen. [PM_EVAL9]

Furthermore, PMs were also excited on having seen dialogues providing novel ideas for them to consider:

Sometime the dialogue can lead on to things beyond the dialogue. This is a precious output for us as a municipality - maybe the output has nothing to do with the list of activities. Sometimes the value is in other areas. [PM_EVAL9]

From the evaluation, it emerged however that PMs face an issue of managing YEAs expectations. In some cases, there was a problem of whether the current state of affairs would allow PMs to deliver on the e-participation results. In other words, while some ideas promoted by YEA may be interesting, some public authorities do not have the means to implement them. In the following excerpt for example, a PM recognises that the local authority lacks the infrastructure to solve the issue of wastewater management that YEAs have been discussing during e-participation:

Yes, some of the problems cannot be solved easily because if there is no infrastructure, example for the wastewater management, if there is no infrastructure no-one can do anything.... [PM_EVAL7] 
The following excerpt shows anyway that YEAs also have an understanding that policy makers may face limits and that a new policy process and implementation may require time to emerge:

I think its not going to change everything from the day to the night and that will be it, [...] but for the young people to be engaged, there is a response required by the town Hall even though the processes are slow because there are a lot of different factors that play a role in application of policy. [YEA_EVAL3]

Moreover, some PMs were wary of the problem that YEAs were expecting instant responses to their inputs perhaps fueled by the communication medium, in a social media like fashion, but that such an instant response was not immediately achievable. PMs remarked that this was an expectation that needed to be managed for the e-participation to be both realistic and successful.

\subsection{Ownership theme}

We have discussed earlier that the ownership dimension of environmental action is an important need and this also relates with dedicated spaces where young people can use their competences and take responsibility for the protection of the environment. In the evaluation questionnaire, we asked whether the platform constitutes a good medium for YEAs to bring their ideas/concerns to PMs. Responses we received were very similar to those we have seen before, with $57 \%(n=103)$ positive responses and $12 \%$ negative $(n=21)$, with a remaining large neutral component.

Some YEAs we interviewed saw the importance of having the e-participation platform as a space where they could exercise their ownership on environmental issues:

I have just been reading the comments and liking them and thinking about different ideas to parks in the near future but yeah people are actually getting involved and I had a chance to read a couple of comments and ideas about them. [YEA_EVAL3]

In the above, the interviewee sees the platform as a space where YEAs had the opportunity to be involved (by reading, commenting etc.) and to express their positions. The following excerpt goes further:

If you suggested to me that tonight, I should go to an exhibition about climate change I wouldn't go, I prefer to stay on my couch, but if I have an application about e-participation, where I can just type my opinion, and I can interact with others and from other regions then this is appealing. [YEA_EVAL4]

In this case, the interviewee seems to argue that traditional spaces (like an exhibit) may not be that attractive to YEAs, however an e-participation platform offers enhanced opportunities to be involved with others, allowing people to exercise their environmental action ownership from anywhere. The following excerpts, further remark on the importance of the platform as a space for YEAs environmental ownership:

I really liked the idea of a platform dedicated to Young People and the idea of relating Young People with the politicians, and them seeing what we think and what we think we need, because we are like the future you know. [YEA_EVAL7] 
I think the platform will help, because although obviously we can go to the door [of the Town Hall] and say 'listen to me' the fact is no-one will, and the platform is going to help us is in this way, so I think it is good. [YEA_EVAL7]

It emerged then from the interviews that with the platform, YEAs thought they could demonstrate to PMs what they think and project this toward the future. Moreover, one of the interviewees argues that direct contact will not help YEAs get their message across to PMs (they saw the Town Hall as a space 'for them not us', it was a physical and mental barrier to participation), but the platform would offer this capacity.

\subsection{Future theme}

A core environmental action need for young people is their capacity to project their actions toward achieving future outcomes. Indeed, young people may be driven to act because they feel they have a role and a duty in making changes for future generations. An important aspect of this relates to the future involvement of young people in the environmental policy-making process. In the questionnaire, we asked YEAs whether they would recommend the future use of the platform to their peers. We had a strong positive response to the question $(77 \%, n=139)$ with the largest set of responses as Strongly Agree (Fig. 7), with very limited negative ones $(n=4<3 \%)$.

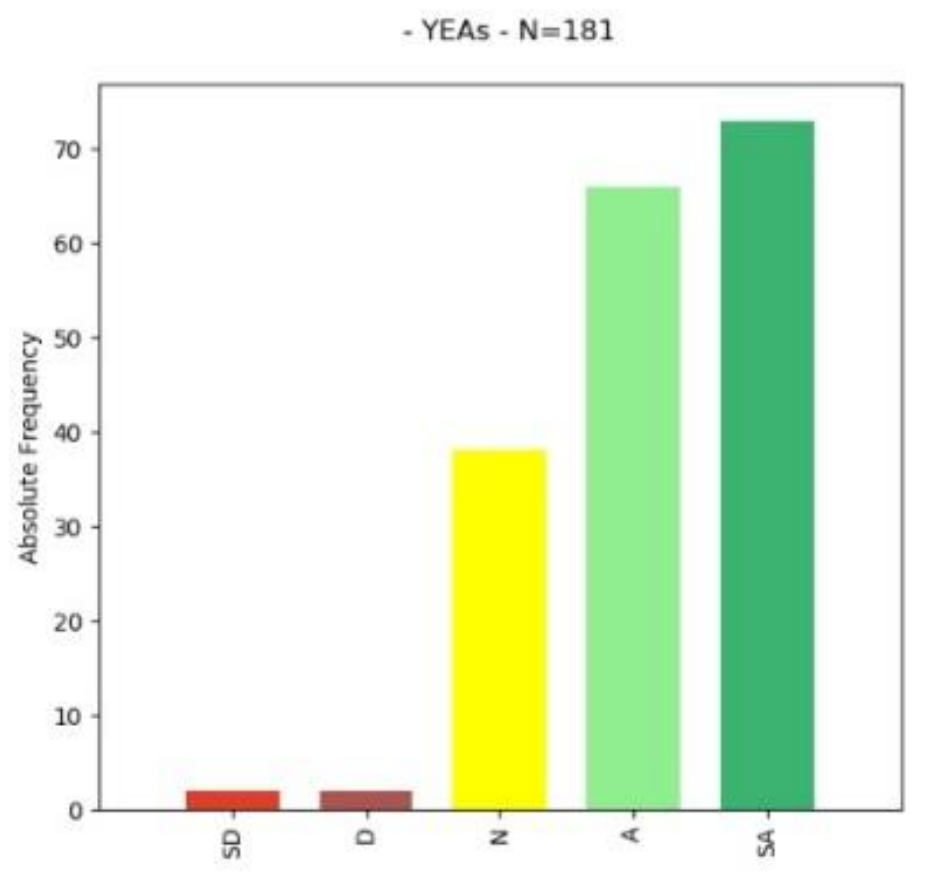

15. I would recommend the STEP platform to other young people

Fig. 7. STEP and YAEs recommending the platform to peers

In the interviews, some YEAs acknowledged that the platform offered the opportunity to, collectively, make a change and they projected their action toward the future. Some of these futures are relatively short-term and related to changes at the level of the municipality/region: 
[the] best thing is the possibility that the different parts of society, different citizens can come together to connect and share ideas. But also at the same time have the connection to the Town Hall in order to make improvements. I really like this opportunity in order to debate and discuss different ideas that, at the end of the day, are going to improve the life of everyone. [YEA_EVAL12]

Other expressions of projection toward the future were long-term and infused with some idealism on changes for future generations or the planet:

The platform is helping because it gets into the citizens and they teach it [environmental knowledge] to the little kids and when they grow up, then they are gonna be aware about it. [YEA_EVAL7]

Or for making YEAs change attitude toward what is important for life, by thinking beyond the immediate situation:

Sometimes, the Young People are like, 'I'm young and I don't care about what is happening, I'm gonna just live the crazy life!' you know and I feel it [STEP] will help us to know a little more about what is happening here. [YEA_EVAL7]

It is clear that YEAs also have long-term aspirations toward the environment and saw the e-participation platform as a tool that could help solve long-term environmental challenges and overcome existing barriers and problems.

\subsection{Direct experience theme}

We have seen in pre-piloting interviews that e-participation in environmental policy-making could have more grip if the process was about local issues on which YEAs have a direct interest. This relates to the direct experience dimension of environmental action and is an important need for eparticipation. In the questionnaire, we asked explicitly whether the platform was supporting YEAs involvement in local environmental issues. We see in Fig. 8 strong positive responses overall (71\%, $n=128)$. 


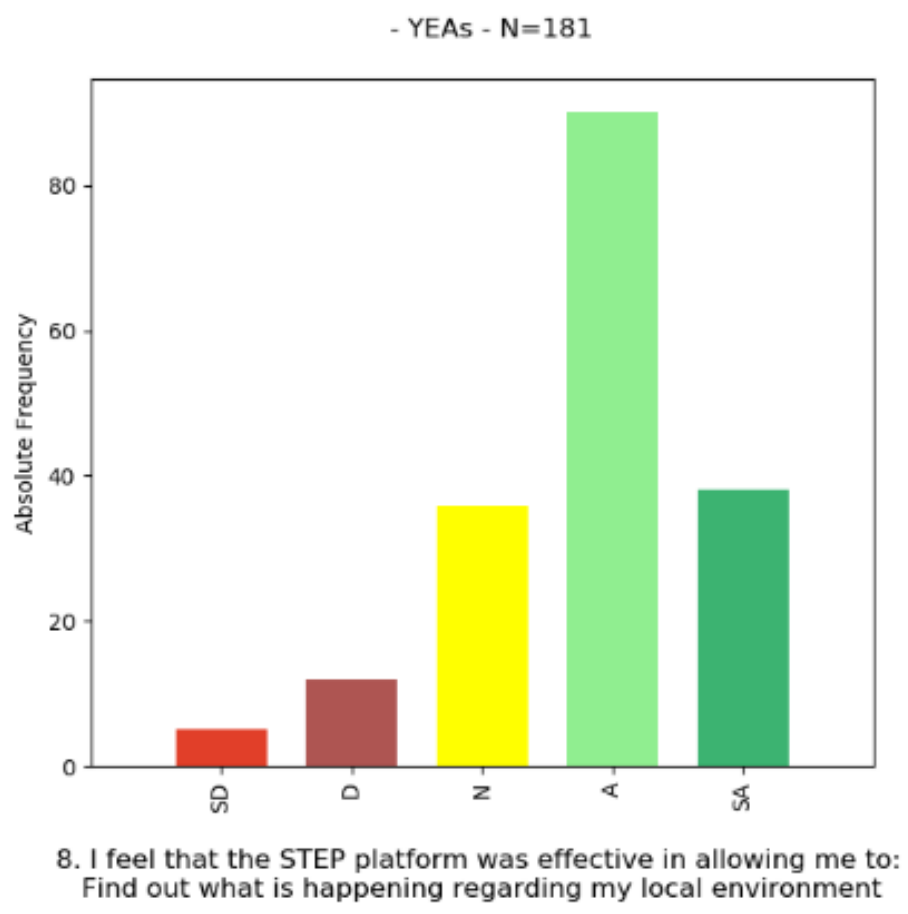

Fig. 8. STEP and YAEs on local environment

What follows in an excerpt from a PM interview acknowledging the importance of the experiential dimension of e-participation for young people:

I think that is what we are saying you have to really know very well your society, what they are expecting, which are the expectations and demands and to try to run some dialogues that are really key for them. [PM_EVAL3]

YEAs also emphasised that e-participation to environmental issues must be tied to what is important for them, rather than on far away problems:

There is a huge environmental problem in the region, Water management is a big issue - everybody knows it. [...] People also really think they don't have the feeling of Climate Change. When you transform the issue into something tangible, then it's easier to talk about it. So for example, Water management is easier to discuss than CO2 emissions and global warming [YEA_EVAL6]

Thus, our evaluation did measure the platform's capacity to support e-participation on local matters, in line with the experiential dimension of environmental action. However, not everything that is local constitutes something of interest for YEAs. One of the pilot regions used the platform for dialogues around Consultations on Environmental Impact Assessments (CEIA). This was not very appealing for YEAs because these documents are rather technical and outside their interest. Below is an excerpt where the respondent makes this clear and compares the CEIA with other local topics that can instead easily drive participation:

So the dialogues about Climate Change and Water Management in the Region, or the Caretta Caretta, these are things that people know about and can form an opinion about and express it. [...] 
When it comes to Environmental Impact Assessment, then, for example the one about the hotel being built, well, people think 'OK - It's not my job to know about this' [YEA_EVAL6]

Below is an excerpt from a PM interview, acknowledging this problem:

....they [YEAs] are more interested in issues put on debate than on the Environmental Impact Assessment, they are technical things containing terms that most young people do not understand, hard for them to express an opinion [PM_EVAL7]

Thus, it is not that "local" always equates to direct experience and immediate interest for YEAs. This is an important lesson showing that the content of the local decision is also important for fostering YEAs environmental action.

\subsection{Summary on environmental action and e-participation}

Table 4 summarises the findings of the evaluation and the relations between environmental action and e-participation.

Table 4. Dimension of Environmental Action in e-participation evaluation

\begin{tabular}{|l|l|}
\hline $\begin{array}{l}\text { Dimensions of Envi- } \\
\text { ronmental Action }\end{array}$ & \multicolumn{1}{c|}{ Environmental Action and e-participation in Evaluation } \\
\hline Experience & $\begin{array}{l}\text { Our analysis suggests that e-participation in environmental policy- } \\
\text { making fares better when the discussion(s) revolves around things } \\
\text { that are tangible to the life of young people. Too technical and "out } \\
\text { of touch" local issues did not drive participation. An e-participation } \\
\text { platform can help young people better understand issues and allow } \\
\text { them to contribute to the local environmental decision-making. }\end{array}$ \\
\hline Stakes in the Future & $\begin{array}{l}\text { The e-participation platform was seen as positive for making } \\
\text { changes and improving the future of the environment. Being lis- } \\
\text { tened to and seeing follow-ups from PMs were mentioned as im- } \\
\text { portant aspects of this. Respondents did see both immediate effects } \\
\text { on the future but also expressed more idealistic positions about } \\
\text { long-term outlooks. }\end{array}$ \\
\hline Participation & $\begin{array}{l}\text { The e-participation platform was seen by young people as a tool fa- } \\
\text { cilitating direct collaboration with PMs on environmental issues. } \\
\text { Although the trust gap was seen as a long-term problem to solve, } \\
\text { directly tied with young people seeing tangible outcomes as results } \\
\text { of their inputs. }\end{array}$ \\
\hline Ownership & $\begin{array}{l}\text { Through the evaluation we have seen that a platform may offer a } \\
\text { space for young people and that a platform offers a medium } \\
\text { through which young people can get across their message to PMs in } \\
\text { relation to environmental change. }\end{array}$ \\
\hline
\end{tabular}




\section{Discussion and Conclusion}

This paper has discussed a research case study that shows how it is possible to connect the concept of environmental action and the process of designing and deploying an e-participation platform for environmental policy-making for young people.

An initial literature analysis supported the identification of the concept of environmental action, over that of environmental attitude or behavior, as a potential basis for the design of environmental e-participation. The main assumption was that the intentionality of environmental action and its participatory nature would support young people's engagement with environmental policy-making. Following this, four core dimensions of the concept of environmental action were identified from the literature as the basis for furthering our research: experience, ownership, participation and stakes in the future. By conducting semi-structured interviews we have identified the environmental action needs of young people in relation to these four dimensions of the concept. The findings from the interviews were then used to create personas and scenarios to elicit end-users environmental action needs and then, via co-creation activities, some solutions to these needs have been envisioned. We have also seen how the effort to embed the concept of environmental action in the platform design was evaluated positively and using environmental action as a lens for the evaluation allowed for the identification of persistent critical issues such as the lack of trust that young people have toward PMs. In summary, the main contribution of our study to research and practice has been that of offering a conceptual basis and a practical example for the design, deployment and piloting of novel solutions for e-participation in environmental policy-making for young people (and possibly beyond). We believe that our conceptual approach and the methods we proposed offer lessons that can be replicable to other environmental e-participation experiences.

A recent book on European E-Democracy in Practice (Hennen et al., 2020) gives some useful insights into the use of digital tools for various democratical methods across a range of areas. The final chapter on improving e-participation at the EU level is particularly insightful, highlighting that the apparent failure of e-democracy to live up to its potential has little to do with digital communication and everything to do with the lack of openness of institutional decision-making processes. Santini \& Carvalho, (2019, p. 178) agree with this sentiment, stating that "online political participation is not only a technological question, but also a question of power. The efforts to enable effective political participation in online platforms go far beyond the creation and implementation of new digital platforms". Transparency, education and seeing that the deliberative process has an impact on the decision making process are all important and our findings from this project confer with these statements.

Royo et al. (2014) have produced a study measuring the level of commitment of local public authorities which excplicitly declared their adherence to the principles of the Aarhus Convention, in particular toward environmental e-participation and the involvement of citizens. The authors show that the level of commitment toward the declaration does not always translate in authorities offering active e-participation processes, using tools such as petitions and others. There seems indeed a gap between intention and practice. The platform produced by the STEP project was designed with the intent of facilitating e-participation processes for local authorities, under the umbrella of the Aarhus 
convention, and the municipalities and regions involved in the piloting benefited from the opportunity to test out novel ideas and instruments which, from our evaluation, helped them in mobilising their youth toward some forms of collective consciousness about environmental issues in their areas. The problem of commitment identified by Royo et al. (2014) is, from what we have seen during our research, often tied with a problem of resources which are not always available, which at the very least require some investements in time and resources, a tailored communication strategy and a number of people (e.g. civil servants or directly policy makers) to be actively involved in the process. It was also clear from our analysis that some of the environmental problems that local authorities face directly may not be of direct interest for young people, as in the case of the environmental impact assessments, and that these cannot foster substantial participation.

e-participation is a concept and a set of experiences which have been developed and researched at least since 2003, the period in which a number of seminal-influential papers were published (Macintosh et al. 2003; Macintosh et al. 2004), accounting for early experimentations and projects. In literature, there have been attempts at systematising the field, either through systematic reviews (Sanford and Rose, 2007; Susha and Grönlund, 2012; Medaglia, 2012; Santini \& Carvalho, 2019)) or frameworks (Tambouris et al. 2007; Wirtz et al. 2018). Studies sought, in particular, to identify what theories and approaches can underpin e-participation. In a systematic analysis, in particular, Susha and Grönlund (2012) showed that much of the literature concentrates on the political communication theory aspects of e-participation, while other contributions relate to contemporary social theory. There are also approaches concentrating on the technological solutions.

A further contribution of our study to research practice is in showing that it is possible to seamlessly connect the above three areas from Susha and Grönlund (2012) - political communication, social theory and technology - in relation to environmental e-participation. Environmental action is a concept that has an increasingly political dimension, with a focus on young people conducting collective action for achieving long-term changes. Moreover, by being based on the notion of social action, environmental action connects with general social theory in relation to the intentionality of action. However, our research also critically supported the technical development of an e-participation platform, through an effort to translate the dimensions of environmental action into practical ideas for designers. As part of the project we also have produced a report highlighting the lessons learned and a potential roadmap for future e-participation endeavours (STEP Consortium, 2017).

Following this, we can, from our results, offer some practical recommendations for the design and conduction of e-participation:

- Prioritise action over attitude: positive attitudes toward issues such as the environment which may be the subject of e-participation may exist, however it is preferable to base a project on supporting action as e-participation ultimately requires people's active involvement. Moreover, the notion of action is more inclusive and supports the participation of both people that are positively engaged with e.g. the environment, but also those who are not and are driven to act for other reasons, such as interests in local matters.

- Design for action: an e-participation platform design should strongly encourage action. We recommend that the dimensions of an action - such as environmental action - are taken as the basis for the design. This can support participating actors in satisfying at least some of 
their needs, such as increasing trust in politics and seeing concrete results from their participation.

- Evaluate the action: the notion of (environmental) action can also serve as the blueprint for evaluating the achievements of e-participation. While it is unlikely that an e-participation process can achieve all its initial goals, it is possible to evaluate what was achieved by measuring the extent to which people perceive their action was supported by a platform, such as, the capacity to influence change.

We acknowledge that this research also has limits. Firstly, our research was part of a larger endeavor aimed at developing a marketable solution. While this was in itself a positive aspect of the project, it also shaped our research. In other words, the focus of the project was as much on building an usable tool for the market of local authorities in Europe as on creating new knowledge on eparticipation processes. For instance, we did not have the capacity to explore certain sociological issues with greater depth and had to concentrate on delivering insights that would make the platform a near to market product. Sociologically speaking, some issues that emerged during our work could have been studied in a more extended manner. For example the issue of trust, in order to propose long-term solutions. Secondly, we concentrated on similarities across the pilots, rather than on differences, as the goal was to find common ground among a variety of experiences. This focus on commonalities did not allow us to concentrate on the political or social specificities of the different pilots Thirdly, on a methodological level, some aspects of our research design did present some limits at the time of conduction. For example, there often is a need to do co-creation with end-users in order to better serve their needs, but in practical terms, some of the aspects we have unveiled via co-creation did not find their way into the final platform. This ultimately may have had an impact on the sense of ownership toward the e-participation platform. Finally, one could argue that in an evaluation participants who contributed to the design of a product would favour that product and rate it higher than a disinterested party. It may be that some of the results of our evaluation suffer from this potential bias. On this aspect we have to consider that we worked on a funded project with a fixed number of piloting local authorities. Both the design and the evaluation had to be conducted within the boundaries of these partners, in order to complete the process of design and testing of the platform. However, the number of YEAs who participated in the piloting activities and in the evaluation activities were far greater in number than the ones who were involved in the early design phases and we are confident that this bias was overall limited in our results.

To conclude, the presented research offers an important lesson for the design of e-participation as it shows that social action and platform design should be connected. Through a series of empirical research activities (comprising interviews, questionnaires and co-creation) we have identified how environmental action, and especially the four dimensions of ownership, participation, stakes in the future and experience, are seen as important needs for young people's involvement in the e-participation process. We have then made an effort to embed the four dimensions of environmental action in the platform design and we have evaluated our results, showing how environmental action can support the delivery of environmental e-participation. 


\section{References}

Ballantyne, R. (1995). Evaluating the impact of teaching/learning experiences during an environmental teacher education course. International Research in Geographical and Environmental Education, 4(1) (1995), 29-46. DOI: https:/ / doi.org/10.1080/10382046.1995.9964957

Boulianne, S., Lalancette, M., \& Ilkiw, D. (2020). "School Strike 4 Climate”: Social Media and the International Youth Protest on Climate Change. Media and Communication, 8(2), 208. DOI: https://doi.org/10.17645/mac.v8i2.2768

Bögeholz, S. (2006). Nature experience and its importance for environmental knowledge, values and action: Recent German empirical contributions. Environmental education research, 12(1) (2006), 65-84. DOI: https://doi.org/10.1080/13504620500526529

Brandtzæg, P. B., Følstad, A., \& Mainsah, H. (2012). Designing for youth civic engagement in social media. Proceedings of the IADIS International Conference Web Based Communities and Social Media 2012, IADIS International Conference Collaborative Technologies 2012, 65-72.

Breiting S. \& Mogensen F. (1999). Action competence and environmental education. Cambridge Journal of Education, 29(3) (1999), 349-353. DOI: https://doi.org/10.1080/0305764990290305

Braun V. \& Clarke V. (2006). Using thematic analysis in psychology. Qualitative research in psychology, 3(2) (2006), 77-101. DOI: https://doi.org/10.1191/1478088706qp063oa

Buček J. \& Smith B. (2000). New approaches to local democracy: direct democracy, participation and 'third sector'. Environment Planning: Government and Policy, 18(1) (February 2000), 3-16. DOI: https://doi.org/10.1068/c9950

Cooper L. T., Bryer A. T. \& Meek W. J. (2006). Citizen-centered collaborative public management. Public Administration Review, 66(s1), (December 2006), 76-88. DOI: https://doi.org/10.1111/j.15406210.2006.00668.x

Cooper A., Reimann R. \& Cronin D. (2007). About face 3: the essentials of interaction design. John Wiley \& Sons.

Dalakiouridou E., Smith S., Tambouris E. \& Tarabanis K. (2012). Electronic participation policies and initiatives in the European Union institutions. Social Science Computer Review, 30(3) (August, 2012), 297-323. DOI: https://doi.org/10.1177/0894439311413436

De Paoli S. \& Forbes P. (2015). Report on Users' Needs and Technical Requirements. Retrieved from http://step4youth.eu/wp-content/uploads/2015/09/D2.2-Report-on-Users-Needs-and-Technical-Requirements.pdf

de Vreede C., Warner A. \& Pitter R. (2014). Facilitating Youth to Take Sustainability Actions: The Potential of Peer Education. The Journal of Environmental Education, 45(1) (2014), 37-56. DOI: https://doi.org/10.1080/00958964.2013.805710

Dietz T., Stern C. P. \& Guagnano A. G. (1998). Social structural and social psychological bases of environmental concern. Environment and behaviour, 30(4) (July 1998) 450-471. DOI: https://doi.org/10.1177/001391659803000402

Eagly H. A. \& Chaiken S. (1993). The psychology of attitudes. Harcourt Brace Jovanovich College Publishers, Fort Worth, TX. 
Emmons M. K. (1997). Perspectives on environmental action: reflection and revision through practical experience. The Journal of Environmental Education, 29(1) (1997), 34-44. DOI: https://doi.org/10.1080/00958969709599105

European Commission. (2013). European youth: Participation in democratic life. Report Special Eurobarometer 375. Retrieved from http://ec.europa.eu/youth/library/reports/flash375_en.pdf

European Commission.(2014). Attitudes of European citizens towards the environment. Report Special Eurobarometer 416. Retrieved from http://ec.europa.eu/public_opinion/archives/ebs/ebs_416_en.pdf

European Commission. (2018). EU Youth Strategy. Retrieved from https://ec.europa.eu/youth/policy/youth-strategy_en

Forbes, P., \& De Paoli, S. (2016). "Probing with the Prototype": Using a Prototype e-participation platform as a Digital Cultural Probe to Investigate Youth Engagement with the Environment. Electronic Government and Electronic Participation: Joint Proceedings of Ongoing Research and Projects of IFIP WG 8.5 EGOV and EPart 2016, 1. DOI: https:// doi.org/10.3233/978-1-61499-670-5-11

Forbes P. \& De Paoli S. (2017). Final Evaluation Report. Retrieved from http://step4youth.eu/wp-content/uploads/2018/03/D5.3-Final-evaluation-report.pdf

Fung A. (2006). Varieties of participation in complex governance. Public administration review, 66 (November 2006), 66-75. DOI: https:// doi.org/10.1111/j.1540-6210.2006.00667.x

Grønhøj A. \& Thøgersen J. (2009). Like father, like son? Intergenerational transmission of values, attitudes, and behaviours in the environmental domain. Journal of Environmental Psychology, 29(4) (December 2009), 414-421. DOI: https://doi.org/10.1016/j.jenvp.2009.05.002

Hennen, L., Van Keulen, I., Korthagen, I., Aichholzer, G., Lindner, R., Rasmus, \& Nielsen, Ø. (eds.) (2020). European E-Democracy in Practice. Springer Nature, Cham. DOI: https://doi.org/10.1007/978-3-03027184-8

Jensen, B. B. \& Schnack K. (1997). The action competence approach in environmental education. Environmental education research, 3(2) (1997), 163-178. DOI: https://doi.org/10.1080/1350462970030205

Jung, J., Petkanic, P., Nan, D., \& Kim, J. H. (2020). When a girl awakened the world: A user and social message analysis of greta thunberg. Sustainability, 12(7), 2707. DOI: https://doi.org/10.3390/su12072707

Lironi E. (2016). Potential and Challenges of E-participation in the European Union. Study for the AFCO Committee, Director General of Internal Policies. (May 2016). Retrieved from http:/ / www.europarl.europa.eu/RegData/etudes/STUD/2016/556949/IPOL_STU(2016)556949_EN.pdf

Medaglia R. (2012). eParticipation research: Moving characterization forward (2006-2011). Government Information Quarterly, 29(3) (July 2012), 346-360. DOI: https:// doi.org/10.1016/j.giq.2012.02.010

Macintosh A., Robson E., Smith E. \& Whyte A. (2003). Electronic democracy and young people. Social science computer review, 21(1) (February 2003), 43-54. DOI: https://doi.org/10.1177/0894439302238970

Macintosh A. (2004). Characterizing e-participation in policy-making. In Proceedings of the 37th Annual Hawaii International Conference on System Sciences, Big Island, HI, USA, 5-8 Jan. 2004. IEEE. 
Mavrodieva, A. V., Rachman, O. K., Harahap, V. B., \& Shaw, R. (2019, October 16). Role of social media as a soft power tool in raising public awareness and engagement in addressing climate change. Climate, 7(10), 122. DOI: https://doi.org/10.3390/cli7100122

Mergel I. (2015). Opening government: Designing open innovation processes to collaborate with external problem solvers. Social Science Computer Review, 33(5) (October 2015), 599-612. DOI: https://doi.org/10.1177/0894439314560851

Omotayo, F., \& Folorunso, M. B. (2020). Use of Social Media for Political Participation by Youths. JeDEM EJournal of EDemocracy and Open Government, 12(1), 133-158. DOI: https://doi.org/10.29379/jedem.v12i1.585

Östman J. (2014). The Influence of Media Use on Environmental Engagement: A Political Socialization Approach. Environmental Communication, 8(1) (2014), 92-109. DOI: https://doi.org/10.1080/17524032.2013.846271

Percy-Smith B. \& Burns D. (2013). Exploring the role of children and young people as agents of change in sustainable community development. Local Environment, 18(3) (2013), 323-339. DOI: https://doi.org/10.1080/13549839.2012.729565

Phang, C. W., \& Kankanhalli, A. (2008). A framework of ICT exploitation for e-participation initiatives. Communications of the ACM, 51(12), 128-132. DOI: https://doi.org/10.1145/1409360.1409385

Prahalad C.K. \& Ramaswamy V. (2000). Co-opting customer competence. Harvard business review, 78(1) (January/February 2000), 79-90.

Putnam D. R. (2001). Bowling alone: The collapse and revival of American community. Simon and Schuster, New York, NY.

Quintelier E. and Vissers S. (2008). The effect of Internet use on political participation: An analysis of survey results for 16-year-olds in Belgium. Social Science Computer Review, 26(4) (Winter 2008), 411-427. DOI: https://doi.org/10.1177/0894439307312631

Royo, S., Yetano, A., \& Acerete, B. (2014). E-participation and environmental protection: Are local governments really committed?. Public Administration Review, 74(1), 87-98. DOI:

https://doi.org/10.1111/puar.12156

Sæbø Ø., Rose J. \& Flak S. L. (2008). The shape of eParticipation: Characterizing an emerging research area. Government Information Quarterly, 25(3) (July 2008), 400-428. DOI: https://doi.org/10.1016/j.giq.2007.04.007

Santini, R. M., \& Carvalho, H. (2019). Online platforms for citizen participation: meta-synthesis and critical analysis of their social and political impacts. Comunicação e Sociedade, 36, 163-182. DOI: https://doi.org/10.17231/comsoc.36(2019).2350

Schusler M. T., Krasny E. M., Peters, J. S. \& Decker J. D. (2009). Developing citizens and communities through youth environmental action. Environmental Education Research, 15(1) (2009), 111-127. DOI: https://doi.org/10.1080/13504620802710581

Sanford C. and Rose J. (2007). Characterizing eparticipation. International Journal of Information Management, 27(6) (February 2008), 406-421. DOI: https://doi.org/10.1016/j.ijinfomgt.2007.08.002 
STEP Consortium (2017). A Roadmap for the delivery of eParticipation: lessons learned from the STEP project. Retrieved from http:/ / step4youth.eu/wp-content/uploads/2018/03/A-Roadmap-for-the-delivery-of-eparticipation-1.pdf

Susha I. and Grönlund ̊. (2012). eParticipation research: Systematizing the field. Government Information Quarterly, 29(3) (July 2012), 373-382. DOI: https://doi.org/10.1016/j.giq.2011.11.005

Tambouris E., Liotas N. \& Tarabanis K.. (2007). A framework for assessing eParticipation projects and tools. In Proceedings of the 40th Annual Hawaii International Conference on System Sciences (HICSS'07), Waikoloa, HI, USA, 3-6 Jan. 2007. IEEE. DOI: https://doi.org/10.1109/HICSS.2007.13

Tindall D.B., Davies S. \& Mauboulès C. (2003). Activism and conservation behavior in an environmental movement: The contradictory effects of gender. Society \& Natural Resources, 16(10) (2003), 909-932. DOI: https://doi.org/10.1080/716100620

Tonn B. (2004). MyEmpowerNet. gov: A proposal to enhance policy e-participation. Social science computer review, 22(3) (Fall 2004), 335-346. DOI: https://doi.org/10.1177/0894439304265248

Van Liere D. K. \& Dunlap E. R. (1980). The social bases of environmental concern: A review of hypotheses, explanations and empirical evidence. Public opinion quarterly, 44(2) (Summer 1980), 181-197. DOI: http://dx.doi.org/10.1086/268583

Vogiatzi, M., Keratidis, C., Schinas, M., Diplaris, S., Yümlü, S., Forbes, P., Papadopoulos, S., Syropoulou, P., Apostolidis, L., Kompatsiaris, I., \& Symeonidou, M. (2017). The step project: Societal and political engagement of young people in environmental issues. Lecture Notes in Computer Science, 10673 LNCS, 148156. DOI: https://doi.org/10.1007/978-3-319-70284-1_12

Weber M. (1922). Economy and Society, reprinted 1968. University of California Press, Berkeley, CA.

Wilson, A., De Paoli, S., Forbes, P., \& Sachy, M. (2018). Creating personas for political and social consciousness in HCI design. Persona Studies, 4(2), 25-46. DOI: https:/ / doi.org/10.21153/psj2018vol4no2art736

Wilson J. S. \& Snell C.. (2010). 'Bad for the penguins... because they need ice and that to live on': an exploratory study into the environmental views, concerns and knowledge of socially disadvantaged young people. Journal of Youth Studies, 13(2) (2010), 151-168. DOI: https://doi.org/10.1080/13676260903233704

Wirtz, B. W., Daiser, P., \& Binkowska, B. (2018). E-participation: A Strategic Framework. International Journal of Public Administration, 41(1), 1-12. DOI: https://doi.org/10.1080/01900692.2016.1242620

Xenos, M., Vromen, A., \& Loader, B. D. (2014). The great equalizer? Patterns of social media use and youth political engagement in three advanced democracies. Information Communication and Society, 17(2), 151167. DOI: https://doi.org/10.1080/1369118X.2013.871318

Yümlü S., Tosunoğlu C. \& Yanmaz L. (2016). Integrated and Tested STEP Platform. Retrieved from http://step4youth.eu/wp-content/uploads/2016/11/D3.2-Integrated-and-tested-STEP-platform.pdf

Zelezny C. L., Chua P. P. \& Aldrich C. (2000). Elaborating on gender differences in environmentalism. Journal of social issues, 56(3) (Fall 200), 443-458. DOI: http://dx.doi.org/10.1111/0022-4537.00177

Zheng, Y. (2017). Explaining Citizens' E-participation Usage. Administration \& Society, 49(3), 423-442. DOI: https://doi.org/10.1177/0095399715593313 


\section{About the Authors}

\section{Stefano De Paoli}

Stefano De Paoli is professor of Digital Society at Abertay University. His research interest includes online collaborative communities, platform design and cybersecurity. He is currently working on a number of research projects creating platforms for collaboration and training including TRIPLE (https://www.gotriple.eu/) and FOREISGHT (https://foresight-h2020.eu/).

\section{Paula Forbes}

Paula Forbes is a post-doc researcher at the Abertay University, Dundee (UK). She is currently working on European research projects (https://www.gotriple.eu/ \& https://northsearegion.eu/i2i). Paula's research interests include user requirements, qualitative methods, digital inclusion, $\mathrm{UX}, \mathrm{HCl}$, e-Health and Sustainability. She has many years of experience working on large European projects and on smaller, local level projects and has published many journal and conference papers. 